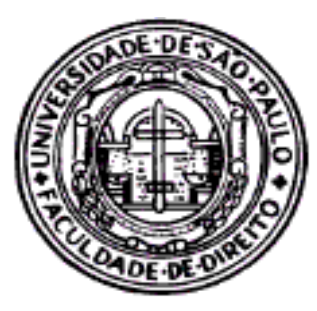

MÁRIO GARCIA JÚNIOR

\title{
A CARACTERIZAÇÃO DA “TRUE SALE" NOS FUNDOS DE INVESTIMENTO EM DIREITOS CREDITÓRIOS NÃO PADRONIZADOS
}

\author{
Dissertação de Mestrado \\ apresentada ao Professor Paulo Fernando \\ Campos Salles de Toledo, do Departamento \\ de Direito Comercial da Faculdade de Direito \\ da Universidade de São Paulo
}

Faculdade de Direito da Universidade de São Paulo - FADUSP

São Paulo 
MÁRIO GARCIA JÚNIOR

\begin{abstract}
A CARACTERIZAÇÃO DA "TRUE SALE" NOS FUNDOS DE INVESTIMENTO EM DIREITOS CREDITÓRIOS NÃO PADRONIZADOS
\end{abstract}

Dissertação apresentada à Banca Examinadora do Programa de Pós-Graduação em Direito, da Faculdade de Direito da Universidade de São Paulo, como exigência parcial para obtenção do título de Mestre em Direito, na área de concentração Direito Comercial sob a orientação do Professor Paulo Fernando Campos Salles de Toledo

Faculdade de Direito da Universidade de São Paulo - FADUSP

São Paulo 


\section{RESUMO}

O intuito do presente trabalho é estudar a caracterização da "true sale" em operações envolvendo Fundos de Investimento em Direitos Creditórios Não Padronizados ("FIDC-NP"), caracterização esta que se constitui na transferência efetiva da propriedade sobre os recebíveis de forma irreversível, irrevogável e, portanto, não sujeita à quaisquer condições ou termos. O estudo é realizado com vistas a entender as posições da doutrina, jurisprudência e das práticas de mercado acerca da "true sale", notadamente nos casos em que são utilizados os FIDCs-NP como veículos numa operação de securitização, bem como nos casos de falência e recuperação judicial do cedente destes recebíveis. Para tanto, serão apresentadas as bases históricas e originárias do mercado de capitais no Brasil, bem como sua implementação na legislação brasileira. Serão estudados, ainda, os institutos que norteiam a caracterização da "true sale", conforme defendida por este trabalho, quais sejam, institutos como o da cessão fiduciária de recebíveis, securitização de recebíveis, fundos de investimento, recuperação judicial e falência, ao mesmo passo que será analisada a legislação que regulamenta tais institutos, notadamente as instruções normativas expedidas pela Comissão de Valores Mobiliários ("CVM") relacionadas aos FIDCs-NP e a Lei no 11.101 de 2005, a chamada Lei de Falência e Recuperação Judicial das Empresas. Será estudada, por fim, a aplicação empírica e teórica do instituto da "true sale" nas hipóteses descritas no art. 1, parágrafo $1^{\circ}$ da Instrução $\mathrm{n}^{\circ} 444$, expedida pela CVM - a qual trata da constituição e funcionamento dos FIDCs-NP.O estudo, portanto, visa principalmente verificar a ocorrência da "true sale" quando da cessão de créditos para um FIDC-NP, de maneira que entendemos ser de suma importância a análise de todos os institutos elencados, tendo em vista que, caso tal cessão dos créditos para o FIDC-NP seja considerada como uma "true sale", na hipóteses de falência, recuperação judicial ou liquidação do cedente, os créditos não serão arrecadados à massa falida, tampouco estarão sujeitos aos efeitos da recuperação judicial, de modo que os investidores que adquiriram títulos lastreados nesses créditos não serão afetados.

Palavras-chaves: "True sale" - Cessão de Créditos - Fundo de Investimento Securitização de Recebíveis - Falência - Recuperação Judicial. 


\begin{abstract}
The purpose of this dissertation is to study the institute of true sale in an operation of securitization of receivables, which a Non-Standardized Receivables Investment Fund (NSRIF) is used as a vehicle. This operation, when typified, entails the effective transfer of the property of the receivables, being this transfer complete, irreversible, irrevocable, and, therefore, non-subjectable to any conditions or terms. The study was made willing to understand the positions of the doctrine, court decisions and market practices about true sale, specially when the NSRIFs are used as vehicles in the securitization, as well when companies in bankruptcy or judicial recovery are involved. So, will be presented the historical bases of the capital market in Brazil, as much as its implementation in Brazilian law. Will be studied, yet, the institutes embracing the typifying of the true sale, which are: fiduciary assignment of credits, securitization of receivables, investment funds, judicial recovery and bankruptcy. The study will also count with the analysis of the laws and regulations around those institutes, specially the normative instructions expedited by "Comissão de Valores Mobiliários - CVM" related to the NSRIF and Law number 11.101 from 2005, the Brazilian Bankruptcy Law. Will be studied, finally, the empiric application of true sale in an assignment of receivables to the NSRIF, so as to we understand that the study of all the institutes mentioned above must be analyzed properly, whereas, if the assignment of the receivables to the NSRIF is considered as a true sale, in cases of bankruptcy, judicial recovery, settlement of the assignor, the receivables won't be considered as their bankruptcy estate, or either be subjectable to its judicial recovery, thus, the investors who bought those secured receivables won't be affected by these events at all.
\end{abstract}

Key Words: True sale - Assignment - Investment Funds - Securitization of Receivables - Bankruptcy - Judicial Recovery. 


\section{AGRADECIMENTOS}

Agradeço à minha esposa Alessandra, por todo o amor, aprendizado e apoio incondicional com os quais me presenteia ao longo dos anos. Agradeço ainda às minhas filhas Giulia e Lara, que foram capazes de entender com amor e carinho os momentos de ausência dedicados a este estudo.

Ao Ferrara Garcia Advogados, pelas discussões, sugestões e colaboração, que me garantiram finalizar este trabalho com louvor. Aos sócios e equipe, agradeço pela troca de informações e pelo constante auxílio em minhas tarefas profissionais durante minha empreitada.

Por fim, agradeço ao meu orientador, Paulo Fernando Campos Salles de Toledo, por ter me concedido a honra de ser seu orientando, por ter confiado em meu trabalho desde o início, pelo incentivo e observações enriquecedoras durante esta trajetória, sem os quais eu não teria sido capaz de desenvolver este trabalho. 


\section{LISTA DE ABREVIATURAS, SIGLAS E DEFINIÇÕES}

\begin{tabular}{|c|c|}
\hline Banco Central do Brasil & "BACEN" \\
\hline Bolsa de Valores do Rio de Janeiro & "BVRJ" \\
\hline Bolsa de Valores de São Paulo & "BOVESPA" \\
\hline Conselho Monetário Nacional & "CMN" \\
\hline Código Civil Brasileiro - Lei no 10.406 de 2002 & "CC" \\
\hline Código de Processo Civil - Lei no 13.105 de 2015 & "CPC" \\
\hline Edição & "ed." \\
\hline Fundo de Investimentos em Direitos Creditórios & "FIDC" \\
\hline $\begin{array}{l}\text { Fundo de Investimentos em Direitos Creditórios Não } \\
\text { Padronizados }\end{array}$ & "FIDC-NP" \\
\hline Fundos de Investimento Imobiliário & "FII" \\
\hline Instrução Normativa expedida pela CVM & "ICVM" \\
\hline $\begin{array}{l}\text { Lei de Falências e Recuperação Judicial - Lei no } 11.101 \text { de } \\
2005\end{array}$ & "LFR" \\
\hline Lei $\mathrm{n}^{\circ} 4.728$ de 1965 , conforme alterada & $\begin{array}{l}\text { "Lei de Mercado de } \\
\text { Capitais" }\end{array}$ \\
\hline Lei do Financiamento Imobiliário - Lei no 9.517 de 1997 & "LSFI" \\
\hline Número & "n”" \\
\hline Página & "p." \\
\hline Páginas & "pp." \\
\hline Programa de Ação Econômica do Governo & "PAEG" \\
\hline Projeto de Lei & "PL" \\
\hline Tribunal de Justiça do Estado do Mato Grosso & "TJMT" \\
\hline Tribunal de Justiça do Estado do Paraná & "TJPR" \\
\hline Tribunal de Justiça do Estado do Rio de Janeiro & "TJRJ" \\
\hline Tribunal de Justiça do Estado de São Paulo & "TJSP" \\
\hline Securities and Exchange Comission & "SEC" \\
\hline Superintendência de Investidores Institucionais da CVM & "SIN" \\
\hline Sociedades de Propósito Específico & "SPE" \\
\hline Superior Tribunal de Justiça & "STJ" \\
\hline Volume & "v." \\
\hline
\end{tabular}




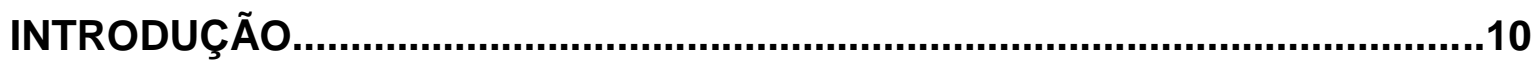

1. HISTÓRICO DO MERCADO DE CAPITAIS BRASILEIRO.............................14

2. MUDANÇA NO MODELO DE INTERMEDIAÇÃO FINANCEIRA.....................21

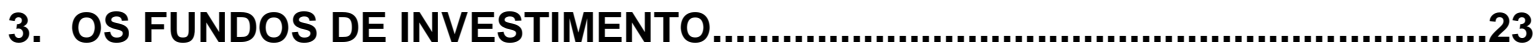

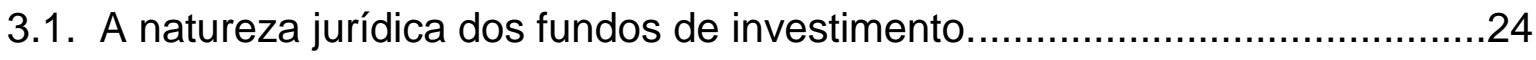

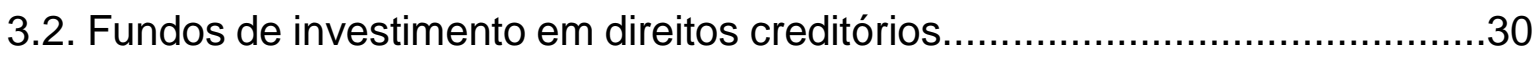

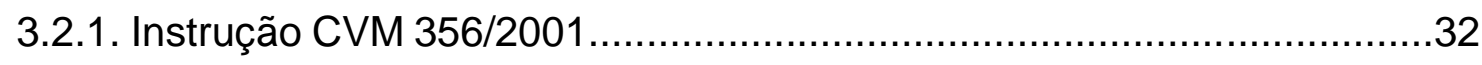

3.2.2. Modificações trazidas pelas instruções CVM 531/2013, 554/2014 e

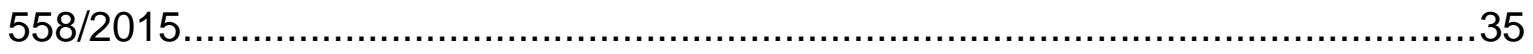

3.3. Fundos de investimento em direitos creditórios não padronizados vis a vis à instrução CVM 444/2006

3.3.1. Instrução CVM 444/2006 e modificações trazidas pela ICVM $554 / 2014$ .45

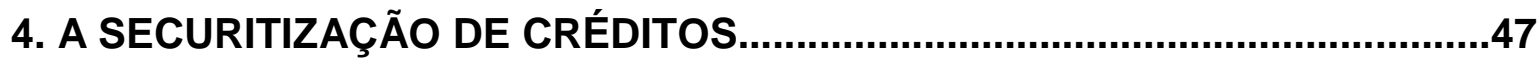

4.1. Histórico do mercado de securitização de créditos.......................................49

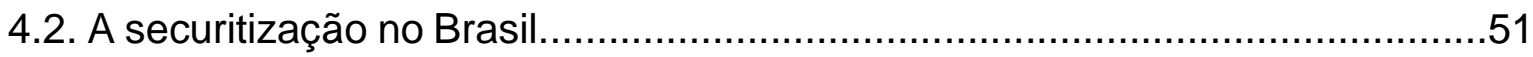

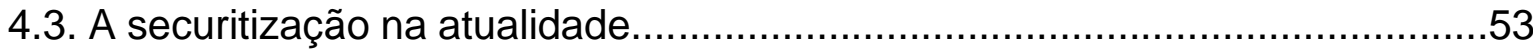

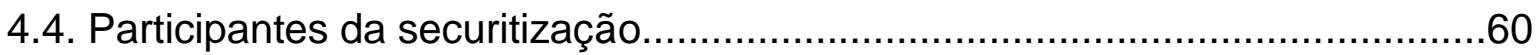

5. CESSÃO FIDUCIÁRIA DE DIREITOS DE CRÉDITO E RECUPERAÇÃO DE

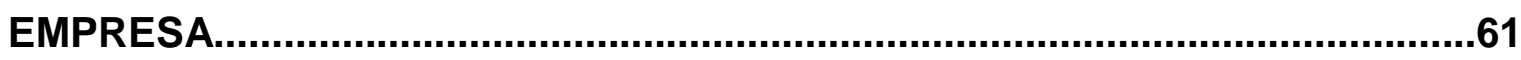

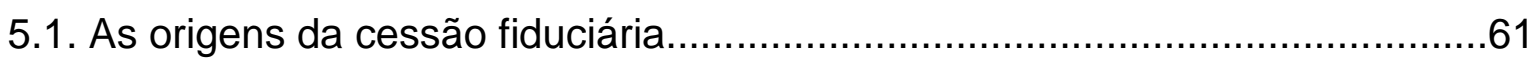

5.2. Efeitos ex ante e ex post da legislação falimentar........................................63

5.3. Recuperação judicial e finalidade dos seus institutos.....................................68

5.4. Efeitos da falência....................................................................................

5.5. Da alienação fiduciária aos direitos de crédito...............................................77

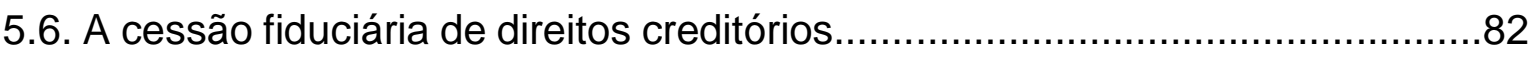

5.7. Cessão fiduciária de direitos creditórios de empresas em recuperação

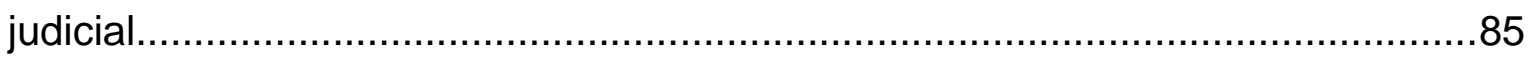

5.8. A cessão fiduciária de direitos creditórios e falência....................................94

6. A CARACTERIZAÇÃO DA “TRUE SALE”...............................................102 
6.1. Conceito

6.2. Aspectos contábeis e econômicos acerca da "true sale"

6.3. Importância da caracterização da "true sale" na securitização de créditos. 118

6.4. A caracterização da "true sale" de créditos para um FIDC Não Padronizado. 119

6.5. A validade de cessão de créditos que estejam vencidos e pendentes de pagamento quando de sua cessão para o FIDC. 122

6.6. Da cessão de créditos decorrentes de receitas públicas originárias ou derivadas da União, dos Estados, do Distrito Federal e dos Municípios, bem como de suas autarquias e fundações. 126

6.7. Da cessão de créditos originados de ações judiciais não transitadas em julgado 129

6.8. Da cessão de créditos cuja constituição ou validade jurídica da cessão para o FIDC seja considerada um fato preponderante de risco 131

6.9. Da validade de cessão de créditos originados de empresas em processo de recuperação judicial ou extrajudicial.

6.10. Da validade de cessão de créditos de existência futura e montante desconhecido, desde que emergentes de relações já constituídas 135

6.11. Da validade de cessão de créditos de natureza diversa, não enquadráveis no disposto do inciso I do art. $2^{\circ}$ da Instrução CVM 356/2001 138

CONCLUSÃO 140 


\section{INTRODUÇÃO}

O presente trabalho tem como escopo de estudo a análise e os efeitos da caracterização da "true sale" nos FIDCs-NP.

Para tanto, em um primeiro momento, serão apresentadas as bases históricas e originárias do mercado de securitização, seu começo embrionário nos Estados Unidos e posterior amadurecimento e consolidação para, posteriormente, ser introduzido na legislação brasileira.

Serão apresentadas algumas definições do termo securitização, incluindo a primeira vez em que foi utilizada tal expressão no mercado norteamericano, tendo sua utilização sido importada para o Brasil, bem como a tradução quase que direta para o português.

Ainda durante a contextualização histórica, sempre essencial para qualquer entendimento e estudo da área humana, serão analisados os princípios que balizam a existência dos fundos de investimento e suas formas mais utilizadas.

Em seguida, será demonstrado como a securitização de recebíveis promove, efetivamente, o processo de "desintermediação financeira", propiciando, consequentemente, e em condições muito favoráveis, a maior liquidez do mercado e a diminuição do seu risco sistêmico em virtude de uma pulverização do risco de investimento.

Seguindo a mesma linha de desenvolvimento, será apresentada uma breve linha do tempo sobre a história da securitização no mercado brasileiro, iniciando-se suas primeiras intenções em projetos de lei, suas negativas no processo legislativo, a exigência do mercado e sua final regulamentação.

Será apresentado, em seguida, o caminho percorrido desde as iniciais concepções da securitização até a sua aplicação por meio dos diversos fundos de investimentos, bem como a forma como a legislação brasileira concebeu tal instituto e o regulamentou, além da maneira pela qual a CVM fiscaliza e estimula este crescente mercado no Brasil.

Além disso, serão apresentadas as principais espécies de fundo de investimento, bem como sua importância, qual legislação aplicável a cada uma 
destas espécies e, também - de maneira sintetizada -, um histórico do mercado brasileiro e sua aplicação aos fundos de investimentos, especialmente no que diz respeito aos fundos de investimentos que possuem por objeto a negociação de direitos creditórios.

Num segundo momento, estando já sedimentada a origem da securitização, seu desenvolvimento e a sua importância para o mercado de crédito e consequente desenvolvimento da economia, passará a dissertação a introduzir as noções necessárias para o entendimento da sistematização na legislação falimentar.

Buscar-se-á demonstrar a relação direta da maneira de se entender o procedimento falimentar das empresas e o seu reflexo, tanto para 0 desenvolvimento do país, quanto para a expansão ou retração do crédito.

Em razão da importância dos recebíveis para o mercado de crédito, tratará a dissertação sobre a concessão de crédito garantido por cessão fiduciária de recebíveis e seus efeitos perante procedimentos de recuperação judicial ou de falência.

Adicionalmente, será analisado qual o regime jurídico que se deve aplicar à cessão fiduciária de direitos creditórios no contexto da LFR.

Serão estudadas as duas correntes doutrinárias e jurisprudenciais existentes acerca da cessão fiduciária de direitos creditórios no âmbito da LFR, quais sejam: a primeira, baseada fundamentalmente no parágrafo terceiro do artigo 49 da LFR, que defende a não subordinação dos créditos objeto de cessão fiduciária ao regime da recuperação judicial; e a segunda que, por sua vez, com embasamento principalmente no parágrafo quinto do artigo 49 e no artigo 47 da referida lei, sustenta a sujeição dos créditos cedidos fiduciariamente ao regime falimentar.

Cada uma das vertentes supramencionadas será analisada de maneira pormenorizada para que se tenha real e total domínio do contexto, do ponto de vista e da caracterização de cada uma.

Ainda no capítulo dedicado à legislação falimentar, será apresentada, também, uma síntese a respeito da cessão fiduciária e sua importância para o mercado de crédito. 
Em seguida, como não poderia deixar de ser, será tratado o instituto da "true sale" e suas principais características, especialmente sua caracterização em operações que lastreiam a constituição de FIDCs-NP.

Com a crescente demanda de captação de recursos por parte de empresas de diversos portes, seja para a manutenção, seja para a expansão de suas atividades comerciais, verifica-se que ocorreu a sofisticação dos instrumentos financeiros disponibilizados às empresas para a referida captação de recursos.

Dentre os instrumentos financeiros criados para a captação de recursos encontram-se os FIDCs, que podem ser ligeiramente definidos como comunhões de recursos que destinam parcela preponderante de seu patrimônio líquido para a aplicação em direitos creditórios diversos.

Os FIDCs são classificados entre padronizados ou não padronizados, classificação esta atinente às espécies de direitos creditórios que compõe tais fundos.

Como a transferência dos direitos creditórios para os FIDC ocorre, via de regra, através da cessão dos mesmos, geralmente pelo tomador dos recursos captados pelo FIDC, de fundamental importância é a caracterização da "true sale", que pode, basicamente, ser conceituada como a cessão de créditos considerada final e definitiva. Este conceito é de fundamental importância no caso de, em uma securitização, sobrevir a falência, liquidação ou recuperação judicial do cedente dos direitos creditórios.

$\mathrm{Na}$ hipótese da cessão dos créditos ser considerada como uma "true sale", em caso de falência, recuperação judicial ou liquidação da cedente, os créditos não serão arrecadados à massa falida, tampouco estarão sujeitos aos efeitos da recuperação judicial, de modo que os investidores que adquiriram títulos lastreados nesses créditos não serão afetados.

Como os direitos creditórios cedidos aos FIDCs-NP possuem diversa e vasta classificação, mister se faz o estudo da caracterização da "true sale" de tais direitos, sendo este, portanto, o objetivo da tese objeto do presente projeto, que tem, destarte, a pretensão de elucidar os diversos aspectos atinentes ao tema proposto. 
Dito de outra forma, tal fração da dissertação terá como objetivo a verificação da ocorrência da "true sale" quando da cessão de créditos para um FIDC-NP.

Para tal desiderato, a dissertação analisará, primeiramente, a validade de cessão de créditos que estejam vencidos e pendentes de pagamento quando de sua cessão para o FIDC.

Examinar-se-á também a validade de cessão de créditos decorrentes de receitas públicas originárias ou derivadas da União, dos Estados, do Distrito Federal e dos Municípios, bem como de suas autarquias e fundações.

Estudar-se-á, na sequência, a cessão de créditos que resultem de ações judiciais em curso, constituam seu objeto de litígio, ou tenham sido judicialmente penhorados ou dados em garantia.

Ainda nesse contexto, a dissertação analisará a cessão de créditos cuja constituição ou validade jurídica da cessão para o FIDC seja considerada um fator preponderante de risco.

A dissertação analisará, ademais, a validade de cessão de créditos originados de empresas em processo de recuperação judicial ou extrajudicial.

Ainda cuidará de outros pontos específicos concernentes à validade de cessão de créditos de existência futura e montante desconhecido, desde que emergentes de relações já constituídas.

Nesse contexto, será examinada a validade de cessão de créditos de natureza diversa, não enquadráveis no disposto no inciso I do artigo $2^{\circ}$ da ICVM nº 356, de 17 de dezembro de 2001.

Igualmente, será analisada a classificação legal dos meios de proteção garantidos ao FIDC quando da cessão dos referidos créditos.

Por fim, tem-se que a dissertação analisará o posicionamento da doutrina e da jurisprudência nacionais e internacionais acerca do tema, especialmente o posicionamento legal norte-americano. 


\section{CONCLUSÃO}

No presente trabalho estudamos a caracterização da "true sale" no tocante às operações de securitização envolvendo FIDCs-NP.

Partimos do histórico brasileiro no mercado de capitais, passando pela época em que o mercado de capitais não era levado a sério no Brasil, não existindo regulamentação alguma acerca do assunto, bem como pelo "boom" da BVRJ em 1971, pela criação da CVM, até o cenário atual, em que o mercado de capitais é totalmente regulamentado, com ótima legislação acerca de governança corporativa, o que passa credibilidade e atrai investidores.

Estudamos os fundos de investimento - os quais possuem natureza jurídica de condomínio - ingressando nos Fundos de Investimento em Direitos Creditórios, os quais são conhecidos no mercado brasileiro como fundos de recebíveis, e regulamentados pela CVM.

Depois, analisamos os FIDCs, que oferecem segurança para os investidores pela regulamentação a que estão sujeitos, bem como pela política de investimento, que deve obedecer aos parâmetros estabelecidos pela CVM, e podem assumir a forma de Não Padronizados, os quais devem possuir política de investimento diferenciada, e só admitem investidores qualificados.

Os FIDCs-NP, objeto do presente estudo, têm como objetivo o investimento em ativos específicos, direitos creditórios distintos daqueles abrangidos anteriormente à sua criação, criando mais flexibilidade para os investidores.

Analisamos os créditos que podem ser cedidos para o FIDC-NP, os quais possuem maior risco de inadimplência e, consequentemente, maior taxa de risco a ser cobrada pelos investidores.

Feitas as considerações acerca dos fundos de investimentos, passamos a estudar o instituto da securitização de recebíveis, criado, por exemplo, para suprir, de forma rápida e segura, a necessidade de caixa de sociedades para aquisições diversas de insumos para produção, manutenção das quantidades estocadas, financiamento e capital de giro. Sempre em busca de dar continuidade a suas atividades. 
Tais empresas, com a securitização, passam a integrar o mercado de capitais na qualidade de originadoras de crédito, o que possibilita que estas captem recursos no mercado com juros menores do que aqueles oferecidos pelas instituições financeiras.

Ato contínuo, a aplicação de capital, pelos investidores, também fica com juros mais atrativos do que as aplicações tradicionais.

A securitização tem como pré requisito a cessão fiduciária de direitos creditórios, a ser realizada pelas chamadas empresas originadoras para um veículo de propósito específico, que pode ser um FIDC ou uma Sociedade por Ações.

Ocorre que, em algumas vezes, a operação de securitização pode ser anulada, após a sua realização, nas hipóteses de falência ou recuperação judicial do devedor dos créditos outrora cedidos.

Por outro lado, estudamos que o entendimento de que a cessão fiduciária de direitos creditórios pode ser anulada nas hipóteses de falência ou recuperação judicial do devedor foi ultrapassado, tendo sido acatado pela doutrina e pela jurisprudência o entendimento de que referida cessão está excluída dos efeitos da falência e recuperação judicial, integrando o rol que consta do artigo 49 da LFR, uma vez que os direitos creditórios constituem bens móveis, bem como porque a cessão fiduciária perfeita e válida, constitui a transferência efetiva dos direitos creditórios, os quais não passam mais a pertencer a quem os cedeu, mas para o cessionário.

Passamos, então, a estudar a "true sale", instituto que ainda não foi devidamente regulamentado no Brasil, tampouco no exterior, de maneira que ainda restam dúvidas acerca do momento em que efetivamente é caracterizada a "true sale".

Das vantagens da "true sale", quando caracterizada, estão a mitigação dos riscos oriundos das operações de securitização e a não ocorrência de situações como a anulação das cessões de direitos creditórios nos casos de falência ou recuperação judicial dos devedores, haja vista que a "true sale" implica na transferência efetiva dos direitos, do cedente para o cessionário, de maneira que 0 cedente passa a não fazer parte da operação, sendo o cessionário o credor o único titular dos direitos sobre o crédito cedido. 
O presente estudo, então, permite concluir que não há nada que vede ou descaracterize a cessão fiduciária de direitos creditórios para um FIDC-NP, mesmo que se tratem de recebíveis lastreados em créditos com risco elevado, os chamados créditos exóticos.

No entanto, a falta de regulamentação acerca do assunto impede que todas as operações de securitização de recebíveis sejam caracterizadas como "true sales", gerando insegurança jurídica capaz de deixar investidores e originadores reticentes no tocante à ingressarem neste tipo de mercado.

Por todos estes motivos, entendemos ser de suma importância o tratamento legal adequado ao instituto da "true sale" no Brasil, o que traria benefícios para a economia do país como um todo: Os beneficiários da regulamentação do instituto seriam, notadamente, os investidores e as empresas que desejam ceder seus créditos para gerar caixa, os quais operariam com a devida segurança jurídica. Dado isto, ocorreria a mitigação dos riscos das operações de securitização, o que acarretaria aumento significativo na adesão dos brasileiros ao mercado de capitais. Ou seja, uma melhora na economia do país, como um todo. 


\section{REFERÊNCIAS BIBLIOGRÁFICAS}

ACIONISTA.

Mercado.

Disponível

em:

<http://www.acionista.com.br/mercado/fidc.htm>.

ALVES, José Carlos Moreira. Da alienação fiduciária em garantia. Rio de Janeiro: Forense, 1987, 3. ed.

ANDREY, Marcos. Comentários à Nova LRFE. São Paulo; Quartier Latin, 2005.

ARAUJO, Aloísio P. De. As leis de falência: uma abordagem econômica, 2002.

ANDIMA. Disponível em: <http://www.andima.com.br/publicacoes/arqs/fidc.pdf>

BALEEIRO, Aliomar. Curso de Direto Tributário. Forense: 1990;

BARRETO FILHO, Oscar. Regime jurídico das sociedades de investimento (“Investment Trust"). São Paulo: Max Limonad, 1956;

BAUR, Dirk G. and JOOSSENS, Elisabeth, The Effect of Credit Risk Transfer on Financial Stability (January 2006). EUR Working Paper No. 21521 EN;

BEBCHUK, Lucian A.; CHANG, Howard. Bargaining and the division of value in corporate reorganization. Journal of Law, Economics and Organization ${ }^{\circ}$ v. 8, 1992.

. Ex ante costs of violating absolute priority in bankruptcy. The Journal of Finance. ํㅡㄴ 1, v. 57, 2002.

BELVILÁQUA, Clóvis. Código Civil. v.4, 1958;

BEZERRA FILHO, Manoel Justino, Lei de Recuperação de Empresas e Falências Comentada: Lei 11.101/2005: comentário artigo por artigo, 10ª․ Edição Revista, Atualizada e Ampliada, São Paulo, Revista dos Tribunais, 2014;

. Jurisprudência da nova Lei de Recuperação de Empresas e Falências, São Paulo, Revista dos Tribunais, 2006;

. Da Fiducia à Securitização: as garantias dos negocios empresarias e o afastamento da jurisdição, Tese de Doutorado, USP, 2006. 
BHATTACHARYA, Anand. e FABBOZZI, Frank J. "The expanding frontiers of asset securitization". Em "Asset-Backed Securities. New Hope: Frank J Fabozzi Associates, 1996;

BLUM, Len, DiANGELO, Chris. Structuring efficient asset-backed transactions. In Asset-Backed Securities. New Hope: Frank J. Fabozzi Associates;

BORGES, Luiz Ferreira Xavier. Securitização como parte da segregação de risco. In Revista do BNDES, v.6, nº 12, 1999, Rio de Janeiro;

BOVESPA: Disponível em: <www.bmfbovespa.com.br>

CABRAL, Antônio da Silva. Cessão de Contratos. São Paulo: Saraiva, 1987;

CAMARGO, Cândido. Da alienação fiduciária em garantia e fundos contábeis de natureza financeira face à Lei de Mercado de Capitais. Arquivos do Ministério da Justiça. Brasília: Ministério da Justiça, 1967.

CAMINHA, Uinie. Securitização. 2. ed. São Paulo: Saraiva, 2007.

CAMPOS, Diogo Leite; PINTO, Cláudia Saavedra. Créditos Futuros, Titularização e Regime Fiscal. Coimbra: Alamedina, 2007.

CANÇADO, Thais Romano; GARCIA, Fábio Gallo. Securitização no Brasil. São Paulo: Atlas, 2007.

CARVALHO, Ernesto Antunes de. Cessão Fiduciária de Direitos e Títulos de Crédito (recebíveis). Revista do Advogado, ano XXIX, nํ 105, setembro de 2009. São Paulo.

CHALHUB, Melhim Namen. Negócio Fiduciário. Rio de Janeiro: Ed. Renovar, 2009.

CHAVES, Natália Cristina. Direito empresarial: securitização de crédito. Belo Horizonte: Del Rey, 2006.

COELHO, Fábio Ulhoa. A Cessão Fiduciária de Títulos de Crédito ou Direitos Creditórios e a Recuperação Judicial do Devedor Cedente. $7^{\mathfrak{a}}$ ed. São Paulo: Saraiva, 2010.

CRIPPA, Carla de Vasconcellos; MENEZES, Caio Campello de. Valor Econômico, publicado na edição de 21 de outubro 2009. Os recebíveis na recuperação judicial. 
CVM.

Disponível

em:

<http://www.cvm.gov.br/decisoes/2002/20020319_R1/20020319_D15.html>

DCl. Disponível em: <http://www.dci.com.br/financas/credito-podre-rende-lucro-de30--a-setor-de-recuperacao-id286940.html>

DE LUCCA; Newton e SIMÃO FILHO, Adalberto (coord.) - Comentários à Nova Lei de Recuperação de Empresas e Falências, São Paulo: Quartier Latin, 2005.

DIAS, Leonardo Adriano Ribeiro. Financiamento na Recuperação Judicial e na Falência. São Paulo: Quartier Latin, 2014.

DOS SANTOS, Claudio Gonçalves e CALADO, Luiz Roberto. Securitização: Novos rumos do mercado financeiro.

ECO, Umberto. Como Se Faz Uma Tese - Perspectiva, 25ª , Edição, 2010.

EDWARDS, Franklin R. and MORRISON, Edward R. Derivatives and the Bankruptcy Code: Why the Special Treament? (August 16, 2004). Columbia Law and Economics Research Paper No. 258.

EIZIRIK, Nelson; GAAL, Ariádna B.; HENRIQUES, Marcus de Freitas; PARENTE, Flávia. Mercado de Capitais, Regime Jurídico. Rio de Janeiro: Renovar, 2008.

EIZIRIK, Nelson Laks. Aspectos Modernos do Direito Societário. Renovar Editora: Rio de Janeiro, 1992.

FRANÇA, Erasmo Valladão Azevedo e Novaes. Temas de Direito Societário, Falimentar e Teoria da Empresa. São Paulo: Malheiros, 2009.

FREITAS, Ricardo de Santos. Natureza Jurídica dos Fundos de Investimentos. São Paulo: Editora Quartier Latin 2006.

Responsabilidade civil dos administradores de fundos de investimento. In: Aspectos atuais do direito do mercado financeiro e de capitais. São Paulo: Dialética, 1999.

FORTUNA, Eduardo. Mercado Financeiro, Produtos e Serviços, Qualitymark, 20. Ed., 2015.

GAGGINI, Fernando Schwatz. Securitização de recebíveis. São Paulo: Ed. Universitária de Dreito, 2003. 
GORTON, G. B., \& SOULELES, N. S. (2005). Special purpose vehicles and securitization ${ }^{\circ}$ SSRN Electronic Journal. doi: 10.2139/ssrn.713782.

HART, Oliver. Different Approaches to Bankruptcy. Governance, Equity and Global Markets, Proceedings of the Annual Bank Conference on Devel 1999. Paris: La Documentation Française, 2000.

HSBC. Para sua empresa. Disponível em: $<$ http://www.hsbc.com.br/1/2/portal/pt/para-sua empresa/investimento/fundosde-investimento/fidc>

JABUR, Gilberto Haddad e PEREIRA JUNIOR, Antonio Jorge (coord.). Direito dos Contratos. São Paulo, Quartier Latin, 2006.

KETTERING, Kenneth C., True Sale of Receivables: A Purposive Analysis (August 12, 2008). American Bankruptcy Institute Law Review, v. 16.

LIMA, I.S, LIMA G.A.S.F de e PIMENTEL, R.C (coord). Curso de Mercado Financeiro. São Paulo, Atlas, 2ª ${ }^{a}$. Ed. 2012.

LANDSMAN, W. R., Peasnell, K. V., \& SHAKESPEARE, C. (2008). Are asset securitizations sales or loans? The Accounting Review, 83(5), 1251-1272. doi:10.2308/accr.2008.83.5.1251.

LEITE, Cristiano da Cruz. O papel do advogado na estruturação de fundos de recebíveis. In: Securitização de ativos - a era da desintermediação financeira. Lucas de Lima Neto (org.). Rio Grande do Sul: Gainvest Publicações.

LOBO, Jorge, em http:/falimentar.blogspot.com/2010/03/cessao-fiduciaria-derecebiveis-na_10.html, acessado em 17 de dezembro de 2011.

LUBBEN, Stephen J., Beyond True Sales - Securitization and Chapter 11. N.Y.U. Journal of Law \& Business, Forthcoming.

MARTORELL, Antônio Navarro. La propriedad Fiduciária. Barcelona: Casa Editorial, 1950.

MATTOS FILHO, Ary Oswaldo e PRADO, Viviane Muller. Tentativas de desenvolvimento do Mercado Acionário Brasileiro desde 1964. Publicado na obra Direito e Economia, 30 anos de Brasil. Série GVLaw. Coord. LIMA, Maria Lucia L. M. Pádua.2012.

MASON, Joseph R., Cliff Risk and the Credit Crisis (November 10, 2008). 
MIGALHAS. Os fundos de investimento em Direitos Creditórios. Disponível em: $<$ http://www.migalhas.com.br/dePeso/16,Ml2481,61044-

Os+Fundos+de+Investimento+em+Direitos+Creditorios>

MOODYS.

$<$ https://www.moodys.com/sites/products/AboutMoodysRatingsAttachments/20017 00000415918.pdf>

MONTEIRO, Washington de Barros. Curso de Direito Civil. Direito das Coisas. 40 ed. Atualização de Carlos Alberto Dabus Maluf. São Paulo: Saraiva, 2010.

MOSQUERA, Roberto Quiroga. Tributação no mercado financeiro e de capitais. São Paulo: Dialética, 1998.

Os princípios informadores do direito do mercado financeiro e de capitais. in Aspectos atuais do direito do mercado financeiro e de capitais. São Paulo: Dialética, 1999.

MUNHOZ, Eduardo S. Anotações sobre os limites do poder jurisdicional na apreciação do plano de recuperação judicial. Revista de Direito Bancário e do Mercado de Capitais. São Paulo, v. 36, abril-junho de 2007.

NEGRÃO, Ricardo. Manual de Direito Comercial e de Empresas. v.3, 2.ed. São Paulo: Saraiva, 2007.

NETO, Eduardo Salomão. Direito Bancário, São Paulo, Atlas, 2005. . O trust e o direito brasileiro. São Paulo: LTr, 1996.

PORTAL DO INVESTIDOR. Glossário. Disponível em: http://www.portaldoinvestidor.gov.br/Serviços/Glossario/tabid/160/Default.aspx $R \& R$ Consulting. The legal foundations of structured finance. In: Practical Techniques for Asset Securitization. New York, 2006.

REYES, Francisco, Direito Societário Norte Americano - Estudo Comparativo, São Paulo: Quartier Latin, 2013.

RODRIGUES, Silvio. Direito Civil: Direito das Coisas. V. 5. São Paulo: Saraiva, 2003.

SCHIPPER, K., \& YOHN, T. L. (2007). Standard-setting issues and academic research related to the accounting for financial asset transfers. Accounting Horizons, 21(1), 59-80. doi:10.2308/acch.2007.21.1.59. 
SHTATNOV, Artem, The Elusive True Sale In Securitization (January 4, 2012).

SOUZA JÚNIOR, Francisco Satiro de (Org.); PITOMBO, Antonio Sérgio A. de Moraes (Org.). Comentários à Lei de Recuperação de Empresas e Falências, 2ª . ed. São Paulo, Revista dos Tribunais, 2007.

TOLEDO, P.F.C.S; ABRAO, C.H. Comentários à Lei de Recuperação de Empresas e Falência, 5. Ed.: Saraiva, 2012.

TOLEDO, P.F.C.S (Org.); SOUZA JÚNIOR, F.S de (Org,). Direito das empresas em crise: problemas e soluções, 1. Ed. São Paulo: Quartier Latin, 2012.

. Recuperação Judicial, a principal inovação da Lei de Recuperação de Empresas - LREF. Revista do Advogado, ano XXV, no 83, set. 2005.

TOMAZETTE, Marlon. Curso de direito empresarial: Falência e Recuperação de Empresas. v. III, 3ª. Ed. São Paulo, Atlas, 2014, v.1.

TROVO, Beatriz Villas Boas Pimentel, Captação de Recursos por empresas em recuperação judicial e Fundos de Investimento em Direitos Creditórios (FIDC), Dissertação de Mestrado, USP, defesa em 29/05/2013.

UQBAR. Securitização. Disponível em: <http://www.uqbar.com.br/institucional/emque/securitizacao.jsp>

VARELA, Antunes. Direito das Obrigações. Rio de Janeiro: Forense .

WALD, Arnold. Curso de Direito Civil Brasileiro - Obrigações e Contratos. 2. ed. São Paulo, Revista dos Tribunais, 1989. 